Research Article

\title{
Shear Resistance Contribution of Constituent Elements Consisting RCS Joint
}

\author{
Eun-Jin Lee $\mathbb{D D}^{1}{ }^{1}$ Jeong-Ho Moon $\mathbb{D D}^{2},{ }^{2}$ and Moon-Sung Lee $\mathbb{D}^{3}$ \\ ${ }^{1}$ Dongyang Structural Engineering \& Remodeling, Seoul, Republic of Korea \\ ${ }^{2}$ Department of Architectural Engineering, Hannam University, Daejeon, Republic of Korea \\ ${ }^{3}$ Division of Architecture and Architectural Engineering, Hanyang University, ERICA Campus, Ansan, Republic of Korea
}

Correspondence should be addressed to Moon-Sung Lee; moonlee@hanyang.ac.kr

Received 21 November 2019; Revised 2 February 2021; Accepted 11 February 2021; Published 28 February 2021

Academic Editor: Michael Yam

Copyright (C) 2021 Eun-Jin Lee et al. This is an open access article distributed under the Creative Commons Attribution License, which permits unrestricted use, distribution, and reproduction in any medium, provided the original work is properly cited.

In this study, constituent elements affecting the shear strength of RCS joints were investigated through experiment and analysis study. A series of five interior RCS beam-column joint specimens, which were classified as JH-type and CP-type, was tested to investigate the contribution of each shear resisting element such as JH (Joint Hoop), CP (Cover Plate), FBP (Face Bearing Plate), E-FBP (Extended Face Bearing Plate), TB (Transverse Beam), and BP (Band Plate). Comparison between experiment and analysis results showed that the stiffness and strength of the RCS joint were reasonably assessed from the analysis. As a result of the analysis, it was found that TB, E-FBP, and CP increased the shear strength by about $15 \%, 14 \%$, and $26 \%$, respectively. For the JHtype specimen, $70 \%$ of the shear strength of the RCS joint is supported by the inner element and $30 \%$ of the shear strength is supported by the outer element. Shear strength contribution ratio of the outer element of CP-type specimen is larger than that of the JH-type specimen. For all specimens except for SNI-1, around 10\% of total shear strength is supported by FBP. The shear strength equation of the RCS joint proposed by ASCE underestimates the contribution of the outer element, while that of M-Kanno tends to overestimate it.

\section{Introduction}

Reinforced concrete and steel (RCS) moment frame system is one of the composite structural systems that consists of reinforced concrete (RC) columns and steel beams. This system has been gaining its popularity recently because costeffective structures could be constructed by using RC columns instead of steel columns especially for long-span frames [1]. Also, the usage of RC columns in this system increases structural damping and lateral stiffness of the buildings compared to those of steel moment frame systems. Although this system is typically adopted for the construction of highrise buildings located in low to moderate seismic region, with appropriate joint details, this system is also proven to be adequate for buildings in the high seismic region $[2,3]$.

During the 1980s and 1990s in Japan, many details of the RCS composite system were proposed, and experimental studies of RCS joint were performed to validate the proposed details [4-7]. Although the research was interesting, the results were limited to quantify the shear force of the joint. Load transfer mechanism of RCS composite joint was studied by Sheikh et al. [8] and Nishimura and Minami [9]. In the US, Deierlein et al. [10] proposed shear strength equations of RCS joint based on the research of Sheikh et al. [8] and Deierlein et al. [10]. This research later came to form ASCE design guidelines for RCS composite systems [11]. Kanno $[12,13]$ carried out experiment on RCS joint and suggested a shear strength equation that considers the effect of TB and BP based on the ASCE equation. Also, during the 1990s the United States-Japan Cooperative Earthquake Engineering Research Program on Composite and Hybrid Structures tested 56 RCS connection subassemblies to investigate the joint transfer mechanism. Deierlein et al. [14] summarized the tested RCS connections from the Joint Program. Although RCS moment frames can be designed with seismic capacity at least equal to traditional steel moment frames and reinforced concrete moment frames, the use of RCS frames in the high seismic area was limited. 
To change this, much research on evaluating the seismic capacity of RCS frames has been performed [15-20], and analytical modeling $[16,21,22]$ and design procedures were developed [16]. Also, hybrid systems that are combined with RCS frames were developed [23].

Although many experimental and analytical studies have been executed to find structural behavior and shear transfer mechanism of RCS joint and shear force equations of RCS joint have been proposed, their applications are limited to certain RCS joint details, since the effect of some elements consisting RCS joint is still unclear. The equations of ASCE and Kanno have a problem estimating accurate shear strength contribution of Transverse Beam (TB), Extended Face Bearing Plate (E-FBP), and Cover Plate (CP). This research focuses on evaluating the accurate shear resistance contribution of each element through experiment and analysis so that the RCS design procedure that is applicable to any joint detail could be developed. To fulfill the purpose of the study, five RCS joint specimens were tested, and an analytical study was performed by using ANSYS software based on the test results.

\section{Constituent Elements of RCS Joint}

Although numerous details of RCS joint have been proposed, most RCS joints are classified as one of these two RCS joints which are Joint Hoop Type RCS joint (JH-type joint) and Cover Plate Type RCS joint (CP-Type joint) as shown in Figure 1. JH-type joint is composed of steel elements such as Longitudinal Steel Beam Web (SW), Longitudinal Steel Beam Flange (SF), Face Bearing Plate (FBP), Extended Face Bearing Plate (E-FBP), and Transverse Beam (TB) and concrete elements such as Inner Concrete (IC), Outer Concrete (OC), and Joint Hoop (JH). As shown in Figure 2, IC is concrete located within the edge of longitudinal steel beam flange and OC is vice versa. Shear strength of IC and OC of RCS joint is estimated by their effective width. As shown in Figure 1, FBPs are installed for both longitudinal beam and Transverse Beam (TB). For JH-type joint, the shear force is primarily resisted by IC, OC, SW, and FBP installed at TB. FBP installed at longitudinal beam provides confinement for IC, which develops inner concrete compression strut. E-FBP installed on longitudinal beam flange and $\mathrm{JH}$ provides restraint for $\mathrm{OC}$, which develops outer concrete compression field. CP-type joint is composed of steel elements such as SW, SF, FBP, Band Plate (BP), Cover Plate (CP), and TB and concrete elements such as IC and OC. BP and CP provide confinement for CP-type joint. Any elements that provide confinement usually increase the shear strength of the RCS joint. To evaluate the contribution of shear strength at the RCS joint, these elements could be divided into inner elements consisting of SW and IC and outer elements consisting of FBP, CP, OC, and JH.

\section{Experimental Study}

3.1. Test Setup and Specimens. A series of five RCS joint specimens, which were classified as JH-type and CP-type, was tested. JH-type specimens used $\mathrm{JH}$ as basic reinforcement while
CP-type specimens used CP instead of JH. Test setup and details of JH-type specimen are shown in Figures 3 and 4. The list of each specimen is shown in Table 1. Three JH-type specimens, SNI-1, STI-1, and STI-2, were tested and effects of their constituent elements such as TB, FBP, and E-FBP were investigated. The standard specimen is SNI-1, the specimen with FBP only. STI-1 is the specimen with FBP and TB. STI-2 is the specimen with FBP, TB, and E-FBP. Two CP-type specimens, LCC-1 and LCC-5, were tested to investigate the effects of TB, FBP, and CP. For CP-type specimen, CP and BP replace $\mathrm{JH}$ and E-FBP of JH-type specimen. LCC1 is a CP-type specimen that fails in shear and LCC-5 is a CP-type specimen that fails in bending. All specimens except LCC-5 were designed to fail at the RCS joint.

Design of the test specimens and cyclic test were performed based on the test procedure of moment resisting frame in ACI Proposed Provisional Standard [24]. The specimens tested were produced on $2 / 3$ scale of the real structures. Also, tests of material properties for both concrete and steel were performed. The average compressive strength of concrete used for the cyclic test was $41.6 \mathrm{MPa}$. Yield and tensile strength of reinforcement and steel section were $432 \mathrm{MPa}$ and $581 \mathrm{MPa}$, respectively.

As shown in Figure 3, cyclic load was applied to both ends of the steel beam asymmetrically using two $980 \mathrm{kN}$ actuators while the constant axial force of $0.1 f_{c}^{\prime} A_{g}$ was applied to the RC column using $2940 \mathrm{kN}$ hydraulic Jack. Displacement controlled lateral cyclic load was used for the test as shown in Figure 5. Drift angles of 1/500, 1/400, 1/285, $1 / 200,1 / 133,1 / 100,1 / 66,1 / 50,1 / 40,1 / 33,1 / 25,1 / 20$, and $1 /$ 17 were applied gradually and each step was applied three times cyclically.

\subsection{Experimental Results}

3.2.1. Crack and Failure. In general, crack development of RCS joint occurs as follows. At first, bending crack occurs at the column, and then the crack develops along the column and shear crack occurs at the joint. After that, the shear crack develops along the face of the column. Composite failure of concrete on top and bottom of steel beam occurs because of shear crack on the side of the column and bearing stress, which is generated from the behavior of beam. Lastly, a horizontal bending crack occurs in the column.

3.2.2. Load-Drift Angle Relationship. Joint shear failure, joint bearing failure, and steel beam bending failure are principal failure modes of the specimens in this experiment. These three failure modes were observed from all specimens during the test. SNI-1 showed shear failure of the panel zone as planned. For STI-1 and STI-2, while shear strength of the panel zone increased in the beginning, a decrease of internal force happened due to bearing failure of concrete on top and bottom of the steel beam, and then eventually the specimens were failed in column shear. LCC-1 rarely showed shear failure tendency due to the excellent constraint effect of $\mathrm{CP}$, and the specimen failed in bearing failure of the column. LCC-5, which is the 


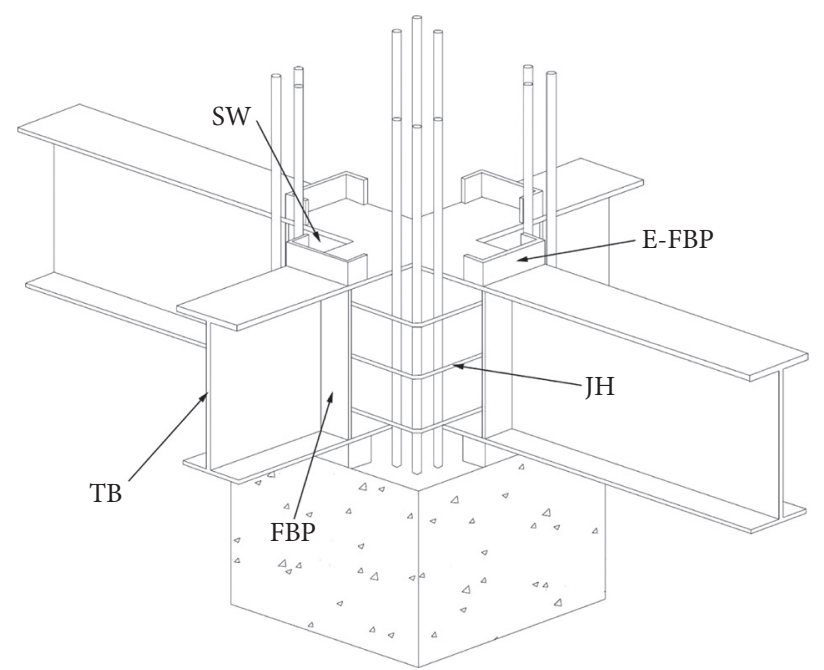

(a)

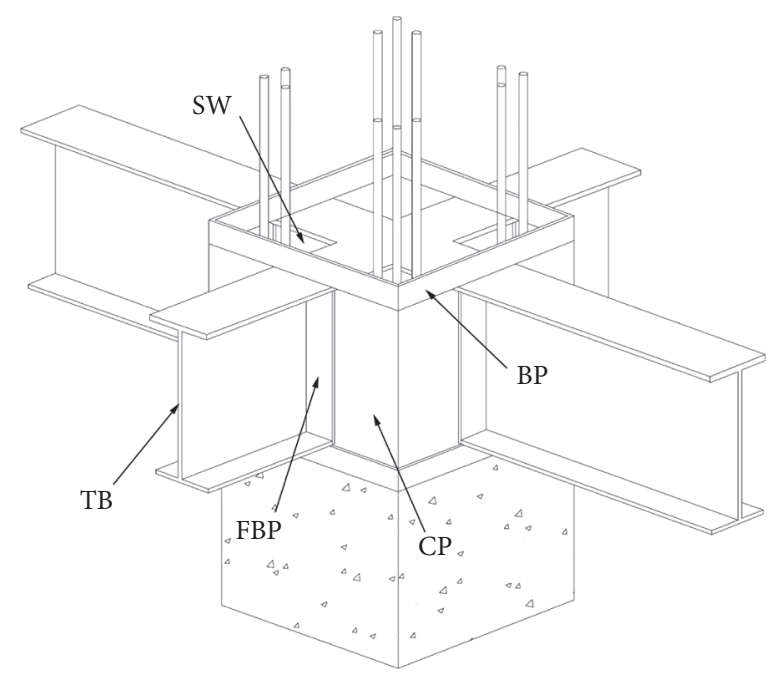

(b)

Figure 1: Details of RCS joint: (a) JH-type RCS joint and (b) CP-type RCS joint.

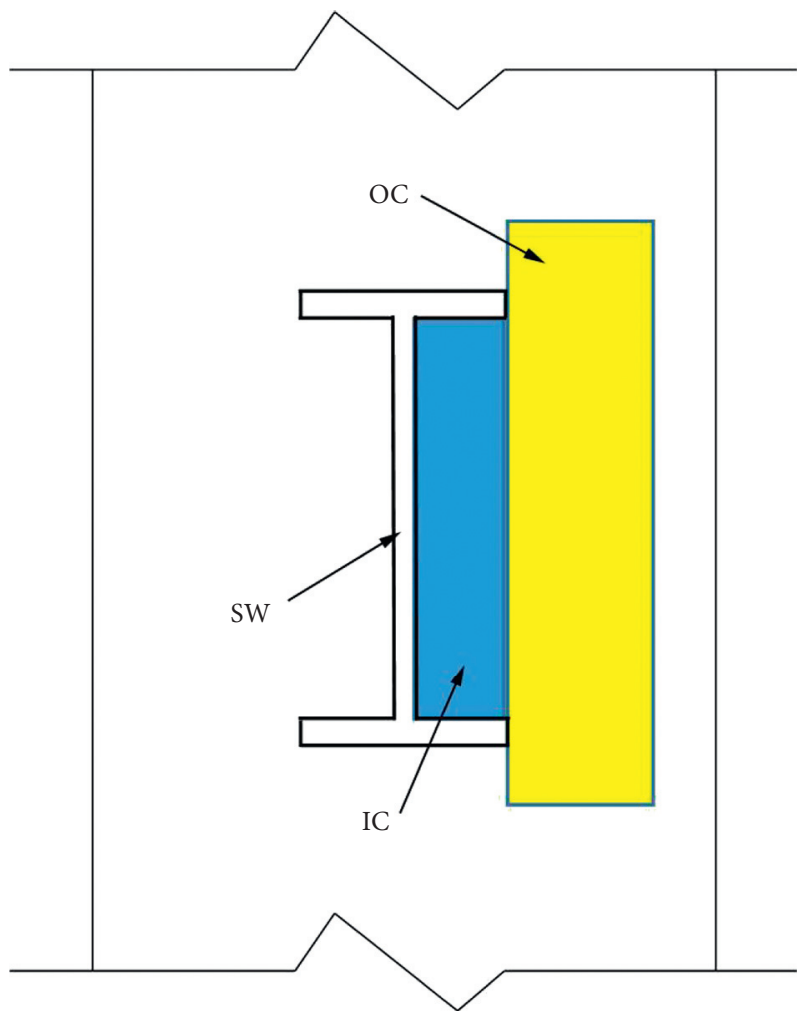

Figure 2: Location of IC, OC, and SW.

bending failure specimen, showed bending failure of the beam as expected. The load-drift angle curve is illustrated in Figure 6.

As shown in Figure 6(a), the load-drift angle curve of SNI-1, the specimen with FBP, shows stable behavior even after the specimen is yielded. However, pinching is somewhat observed from this specimen because of the bearing force on the top and bottom of the steel beam, which results in composition failure. In the case of STI-1,

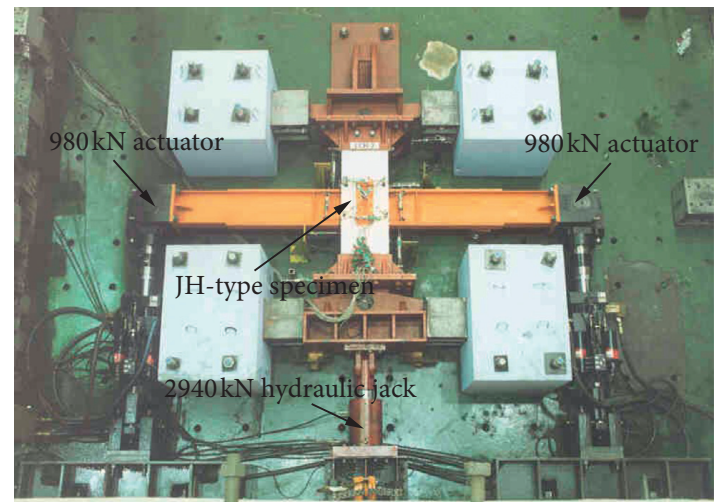

FIgURE 3: Test setup.

the specimen with TB and FBP, stiffness of the specimen increased due to restraint of $\mathrm{TB}$ at the joint, but the strength of the specimen decreased abruptly because of shear failure at the column. The strength of STI-2, the specimen with TB, FBP, and E-FBP, increased a little bit compared to that of SNI-1 and STI-1, and the maximum shear strength was decided by shear failure at the column. Panel zone shear strength of STI-2 was not found from this experiment because the specimen failed in column shear. TB and E-FBP of STI-2 not only increased shear strength of the RCS joint but also improved the energy dissipation capacity of the joint. As shown in Figure 6(d), the loaddrift angle curve of LCC-1, the specimen with CP and BP that fails in shear, shows less pinching effect than that of JH-type specimens. Decrease of width and number of cracks near the joint at failure affected the small pinching effect of LCC-1. In the case of LCC-5, the specimen with $\mathrm{CP}$ and BP that fails in bending, the joint was barely damaged because of the excellent confinement effect of CP and increase of bearing strength due to BP. As shown in Figure 6(e), the load-drift angle curve of LCC-5 exhibits 

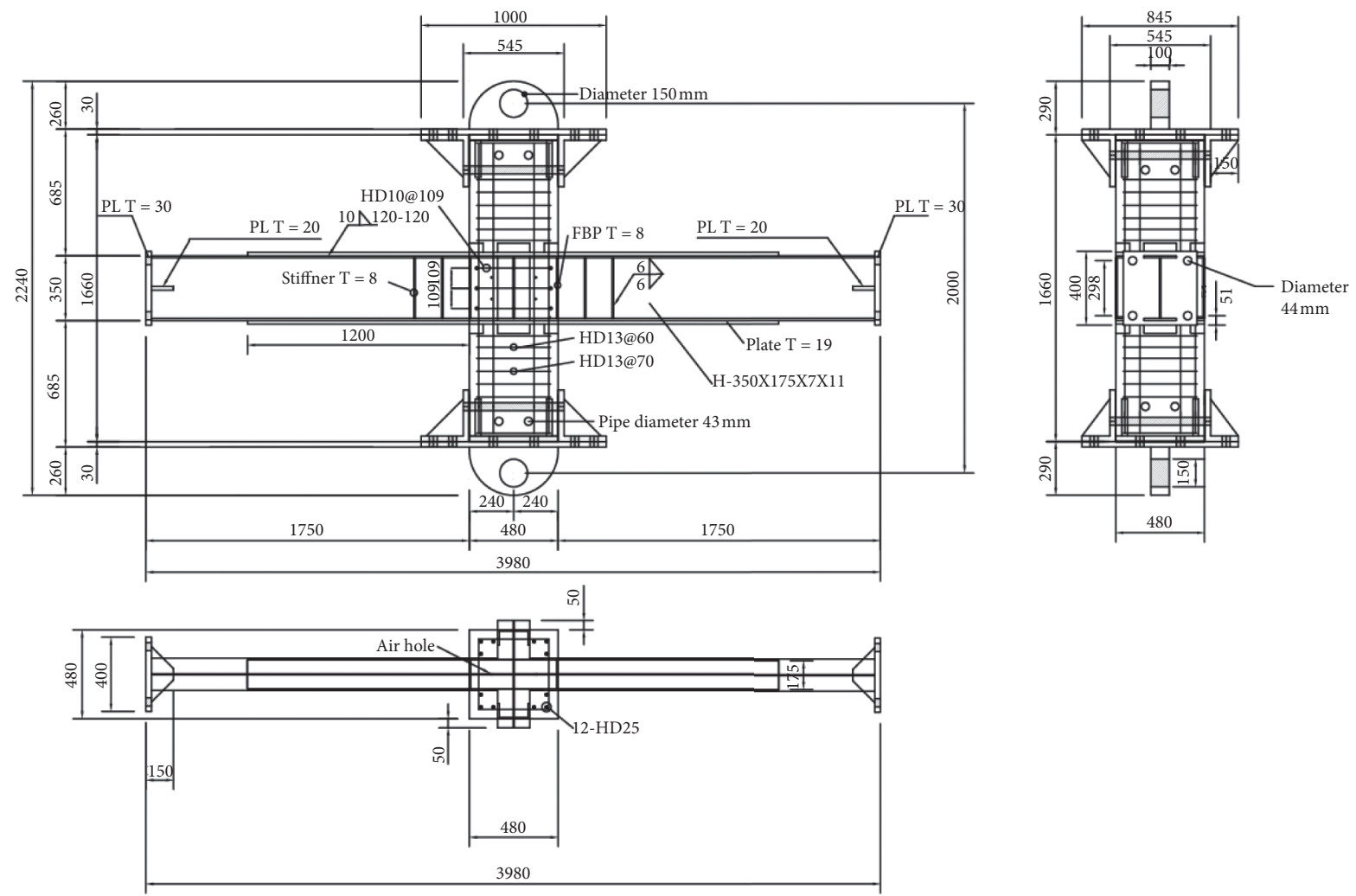

FIgURE 4: Dimensions of STI-2 specimen.

typical moment resisting joint behavior that has excellent energy dissipation capacity without pinching.

Although SNI-1, STI-1, STI-2, and LCC-1 were supposed to reach maximum strength due to shear failure of the panel zone, STI-1, STI-2, and LCC-1 failed in different failure modes. The shear strength from the test is larger than the predicted shear strength using the existing shear strength equation of the RCS joint since this equation is not able to consider the increase of shear strength due to TB and CP. In addition, the maximum strength of the test could increase by around 15\% compared to the predicted strength using the strength equation of Sheikh and Deierlein, because this equation determines the maximum strength when total joint distortion of $1 \%$ is reached.

3.2.3. Change of Maximum Strength. The maximum strength of each specimen at each load cycle is presented in Figure 7. STI-1 and STI-2, JH-type specimen with TB, show a little bit larger strength than that of SNI-1, specimen without $\mathrm{TB}$, in the elastic region, but after the elastic region is passed all JH-type specimens exhibit similar strength until the $30^{\text {th }}$ cycle $(R=1 / 33)$. After the $30^{\text {th }}$ cycle, Figure $7(a)$ shows a distinct strength difference between the JH-type specimens and SNI-1. STI-2 shows 33.5\% and 8.3\% higher strength than that of SNI-1 and STI-1, respectively. While the strength of SNI-1 did not increase due to shear distortion of the panel zone, the strength of STI-1 increased due to reduction of shear distortion because of restraint provided by TB, and the strength of STI- 2 increased further due to additional confinement provided by E-FBP against shear distortion. However, accurate assessment of the strength of STI-1 and STI-2 is difficult because these specimens were failed in column shear rather than panel zone shear failure.

For CP-type specimens, LCC-1 shows about a $26.2 \%$ increase of strength compared to that of STI-2, since CP has a better confinement effect than that of $\mathrm{JH}$ and contributes to resisting shear force transferred to SW.

3.2.4. Strain of Shear Resistance Element. As shown in Figure 8, strain gauges and rosette gauges were installed to measure the strain of each constituent element of the specimens. Figures 9 shows the strain of the shear resisting element between the specimens. In order to analyze the shear resisting element of the joint, the strain between IC and OC is compared. As shown in Figure 8(e), IC is concrete located within the edge of the steel beam flange and OC is vice versa. The strain of IC and OC, which is measured from the strain gauges embedded in concrete at the joint, is presented in Figures 9(a) and 9(b). These strain gauges were installed at an inclined direction as shown in Figure 8(d). Figure 9(a) shows the strain of composite strut of IC. In the beginning, a similar strain is observed for all specimens, but the strain of LCC-1 increases after a drift angle of 0.02. An increase of strain means gradual decrease of shear resistance contribution of the inner composite strut after yield of the specimen. As shown in Figure 9(b), the overall behavior of OC is similar to that of IC before yield, but the strain of the outer composite field of STI- 2 and STI- 1 is larger than that of 
TABLe 1: List of specimens.

\begin{tabular}{llll}
\hline Specimen & Type & Joint reinforcements & Failure mode \\
\hline SNI-1 & $\mathrm{JH}$ & $\mathrm{FBP}$ & Shape
\end{tabular}

STI-1

JH

FBP, TB

Shear

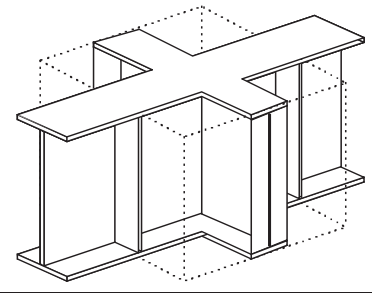

STI-2

JH

FBP, TB, E-FBP

Shear

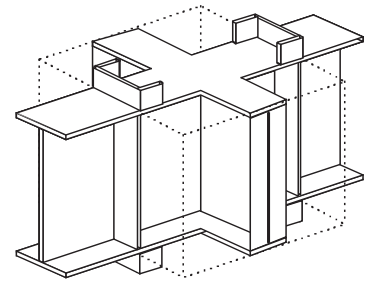

LCC-1

CP

FBP, TB, BP

Shear

LCC-5

CP

FBP, TB, BP

Flexure

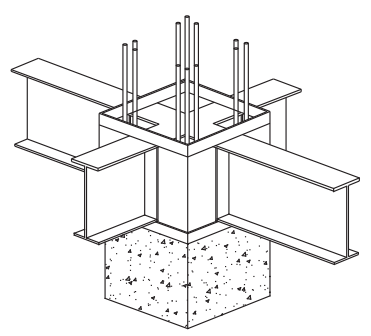

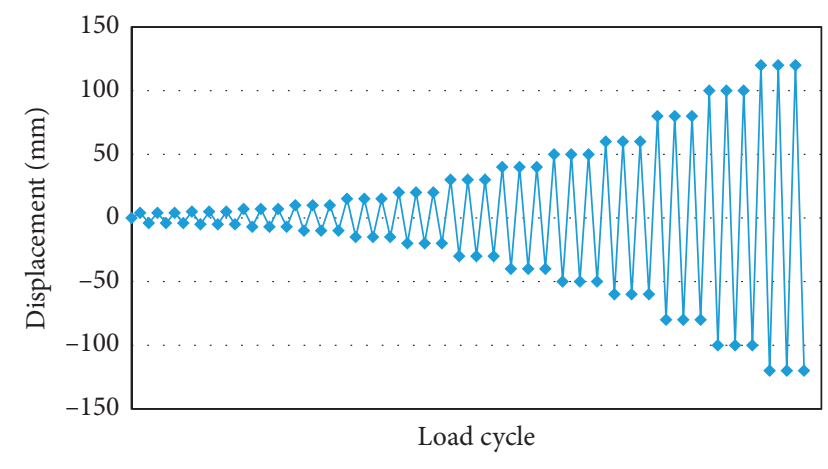

Figure 5: Hysteretic load cycle.

the inner composite strut after yield. Distinct increase of the strain of STI-2 shows the significance of E-FBP, the channel section installed on top of the steel flange, which contributes to developing the outer concrete composite field. The strain of IC and OC of CP-type specimen is larger than that of $\mathrm{JH}$ type specimen. This results in a smaller shear resisting contribution of concrete of CP-type specimen than that of
$\mathrm{JH}$-type specimen. At failure inner element is confined by $\mathrm{JH}$ or CP as well as a steel beam, while the outer element is restrained by $\mathrm{JH}$ or $\mathrm{CP}$.

In order to investigate shear stress on SW at the joint, the strain from the gauge attached to the center of SW is analyzed. These strains are shown in Figure 9(c). Web of all specimens yielded in the test, and according to Kanno's research RCS specimens yield when $40 \%$ of maximum strength is reached. In this study, test specimens yielded at a drift angle of 0.01-0.02 and load of about $147 \mathrm{kN}$, which is about $40-50 \%$ of the maximum strength of the specimens. Based on the overall experimental results, the early yield of SW did not affect the behavior of the specimens significantly, since resistance against external force gradually moves from SW to concrete, $\mathrm{JH}$, and $\mathrm{CP}$ at the joint.

The strain of CP and JH is shown in Figure 9(d). For JHtype specimens, JH did not contribute much to shear resistance because large strain occurred after the yield of $\mathrm{JH}$. On the other hand, CP of CP-type specimen exhibited small strain throughout the test, and the stress contribution capacity of CP was excellent when failure of the joint occurred. 


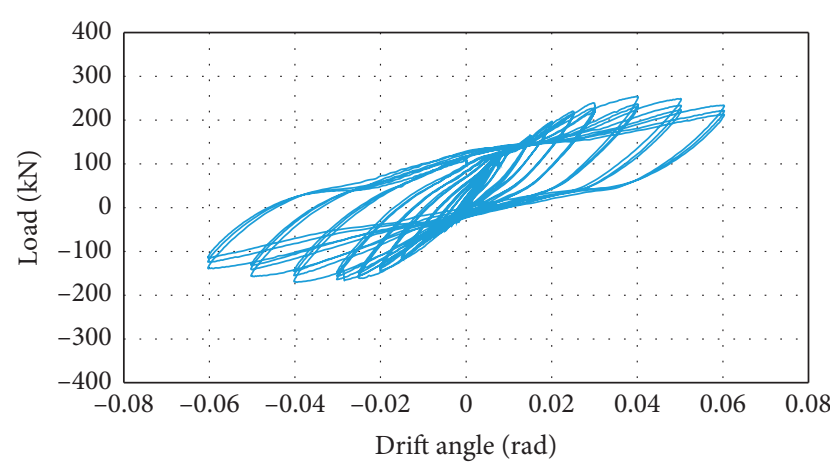

(a)

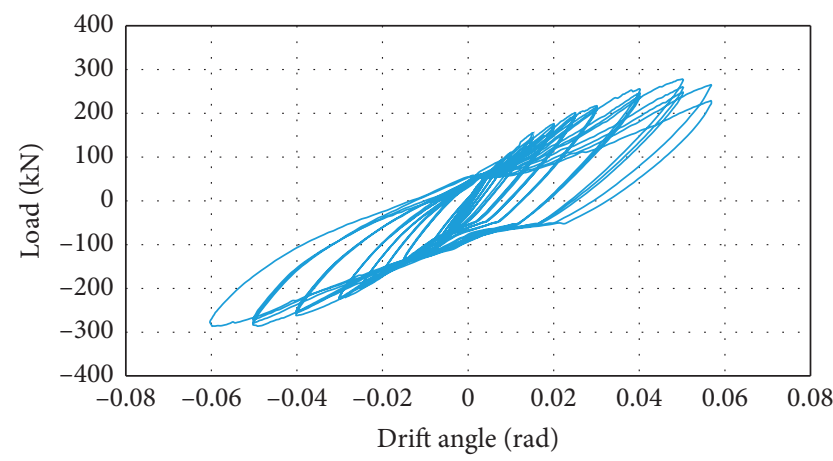

(c)

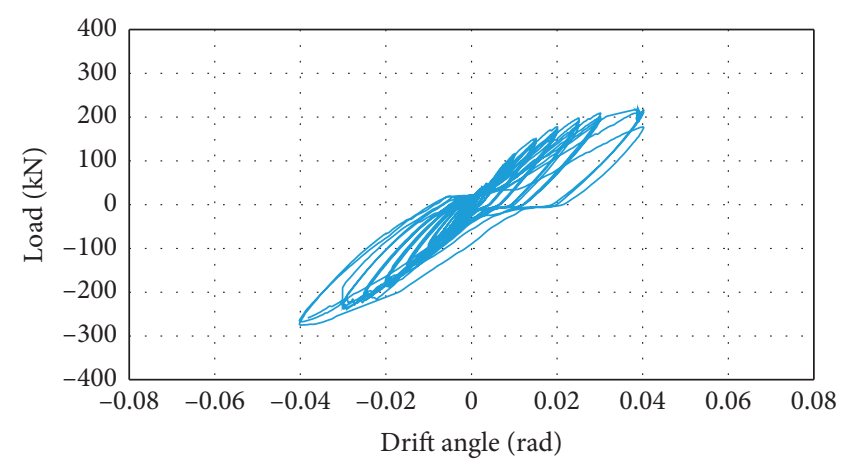

(b)

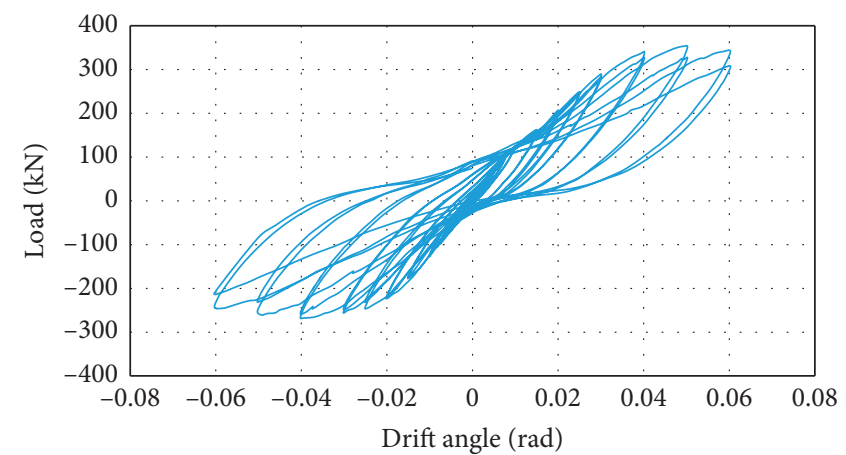

(d)

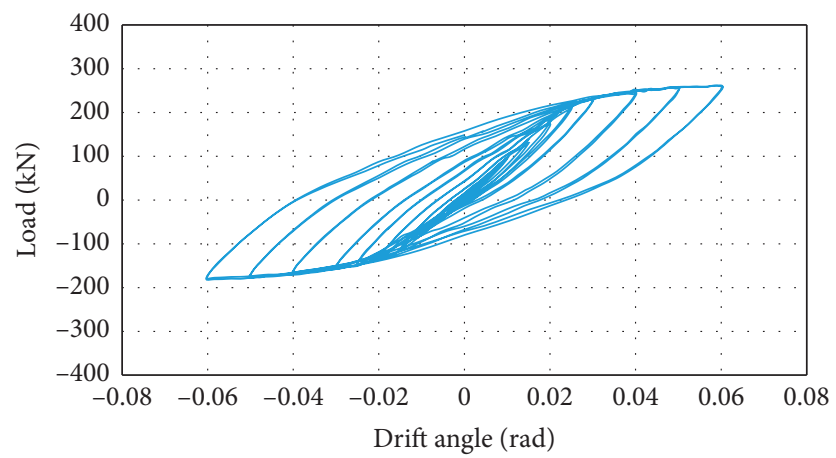

(e)

Figure 6: Load versus drift angle. (a) SNI-1. (b) STI-1. (c) STI-2. (d) LCC-1. (e) LCC-5.

\section{Finite Element Analysis}

4.1. Analysis Model. Nonlinear finite element analysis was executed so that the performance of RCS joints could be predicted. The finite element model of the RCS joints was developed using ANSYS software and calibrated to the experiment results. As shown in Figure 10, a three-dimensional eight-node solid element was used for modeling of concrete. Concrete crushing and cracking and shear stiffness reduction across cracks are able to be represented using this element. This element is also capable of modeling rebars up to three materials. Rebar was assumed to be distributed based on the reinforcement ratio where rebar was present. Modeling of longitudinal reinforcement and hoop were defined separately.

Characteristics of crack at the integration point of the element was defined by the stress-strain curve of principal stress direction shown in Figure 11. When a crack occurs in concrete, usually shear stiffness is reduced. The shear transfer factor is very important when the element is calibrated to the experiment results. This factor takes into account the shear stiffness reduction where the crack is present. In this study, the shear transfer factor of 0.125 , the value used by Stehle et al. [25], was used when crack opens and that of 0.85 , default value from ANSYS, was used when crack closes, since it gave the best calibration of the experiment results. The concept of failure criterion was adopted when the crushing of concrete was considered. In a multiaxis stress state, William and Warnke's five-variable model, shown in Figure 12, was used for the criteria of concrete crushing failure [26]. Rebar is responsible for the tensile strength of reinforced concrete member after concrete crack occurs. A bilinear model was used for modeling of rebar. The yield stress from the material experiment was used for analysis and slope after yield was assumed to be 0.01 . 


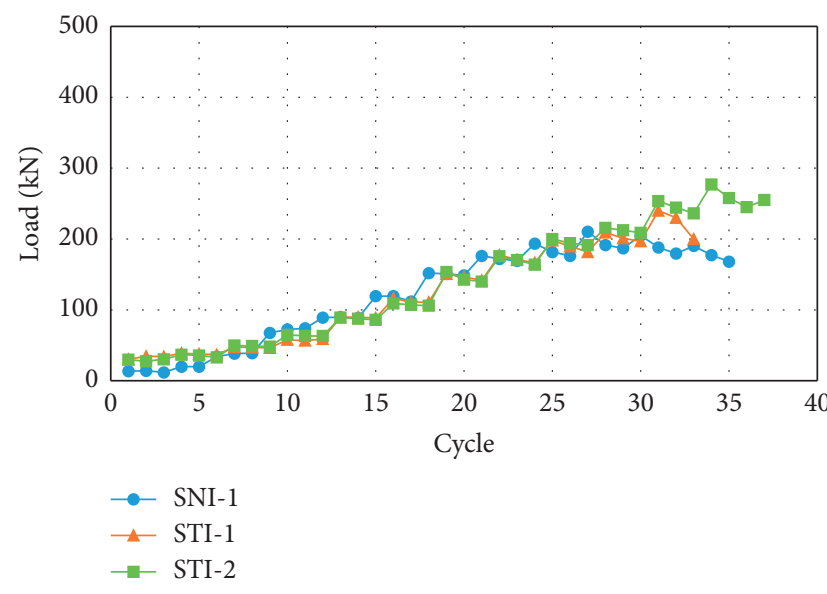

(a)

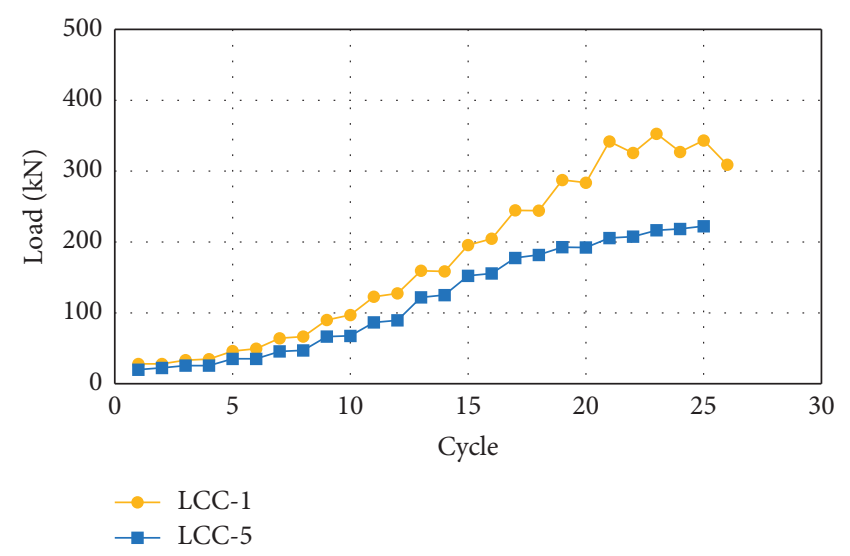

(b)

Figure 7: Change of maximum strength. (a) JH-type specimens. (b) CP-type specimens.

A three-dimensional shell element, which is aeolotropic material having 4 nodes and 4-directional thickness, was used for modeling of the steel material. In this study, infinite inplane stiffness was assumed and von Mises yield criterion and kinematic hardening law were used for nonlinear modeling of the element. The yield stress and stress-strain curve of steel were decided based on the material experiment.

Since the RCS joint did not exhibit a bonding problem between concrete and steel during the experiment, the nodes shared by two elements were rigidly connected in the modeling. For modeling of reinforcing elements such as FBP, CP, and E-FBP, a small interval between these elements and steel beam was added to help the postprocessing procedure. However, these elements and steel beam were connected using the rigid link so that the degree of freedom of the elements was dependent on that of the steel beam since the actual elements and steel beam were rigidly connected.

4.2. Result of Analysis. Comparison between the experimental value and analysis value was executed, and a fairly close result was assessed between them. When CP was installed instead of $\mathrm{JH}$, the specimen displayed excellent strength. In addition, for the CP-type specimen, the shear failure specimen exhibits a very close result to the experimental result until maximum strength is reached, and the bending failure specimen shows very similar behavior until after yield. When the test was performed, the shear contribution of each element was not able to be analyzed due to limitations on attaching gauges at the necessary position and some of the unstable results during the test because of minute vibration. However, through this analysis, shear strength contribution of each element, contribution ratio, and behavior of RCS joint are cleared for both JH-type and CP-type specimens.

4.2.1. Comparison of Experiment and Analysis Result. The load-displacement relationship of experiment and analysis result is shown in Figure 13. A strength comparison between the experimental value and analysis value is presented in Table 2. For all cases, the initial stiffness was excellently anticipated, which was within $10 \%$ error. As shown in Table 2, most strengths from the analysis were reasonably assessed within $10 \%$ error excluding the yield strengths of SNI-1 and STI-1. To find TB's effect on increasing shear strength of joint, strength of SNI-1 and STI-1 is compared because the only difference between SNI-1 and STI-1 is TB. A similar approach is used for finding the shear force increasing effect of E-FBP and CP. As shown in Table 2, the maximum shear strength of SNI-1, STI-1, STI-2, and LLC-1 was $229.18 \mathrm{kN}, 263.25 \mathrm{kN}, 299.42 \mathrm{kN}$, and $377.74 \mathrm{kN}$, respectively. TB, E-FBP, and CP increased the shear force by about $15 \%, 14 \%$, and $26 \%$, respectively. TB, E-FBP, and CP provided additional confinement to STI-1, STI-2, and LLC1 , respectively, and these shear resistance elements significantly affected the increase of the shear strength of the joint.

Shear failure specimen reached failure without showing strength reduction effect after maximum strength in the analysis. For moment failure specimen, strength increased continuously, since analysis material model of rebar and steel beam results in a continuous increase of strength after yield. The analysis of SNI-1 presented a very unstable result due to sudden shear, and it was very difficult to find convergence value because it reached near maximum strength around the yield point. Unlike the experimental result, SNI1 showed maximum strength right after yield due to insufficient ductility and showed a diverging result.

STI-1 showed more ductile behavior than SNI-1 due to $\mathrm{TB}$, and it was possible to find a stable analysis result, but the expected yield strength of the analysis was somewhat different from that of the experiment. It was because the offset method was used when yield strength was estimated for the experiment unlike the yield strength of analysis, which assumes that all materials display perfect capacity.

For CP-type specimen, shear crack at the joint is reduced and delayed due to the constraint effect provided by $\mathrm{BP}$ and CP. The CP-type specimen showed better stiffness and strength than the JH-type specimen since stress concentration at the joint was prevented for the CP-type specimen. 


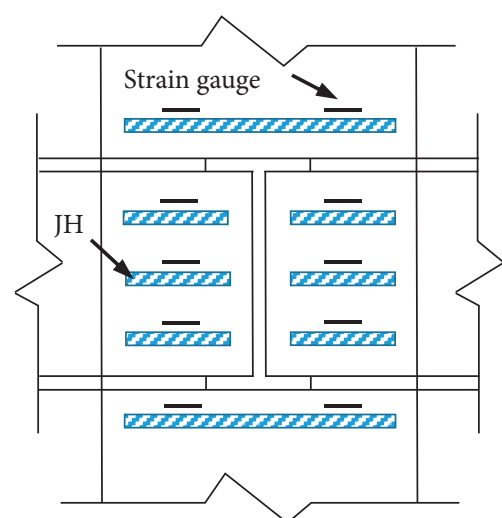

(a)

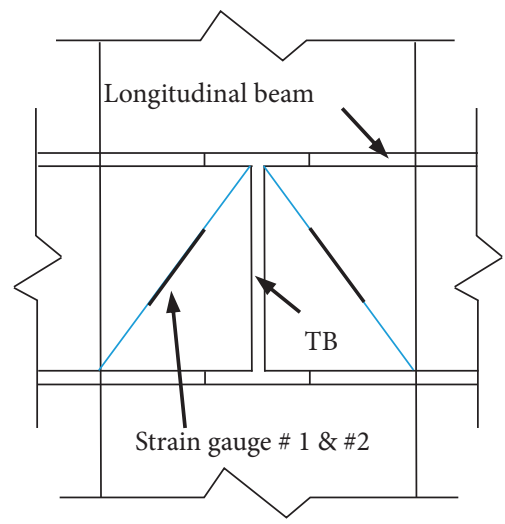

(d)

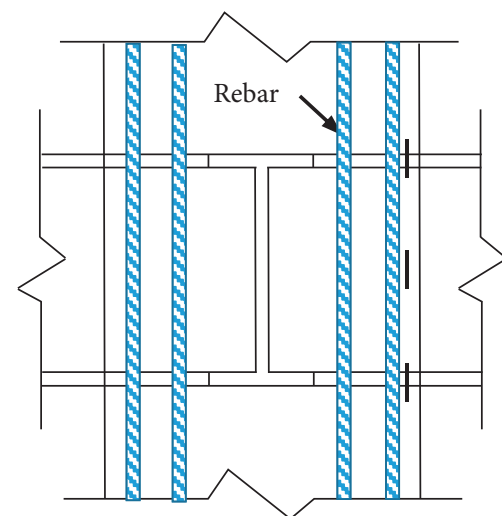

(b)

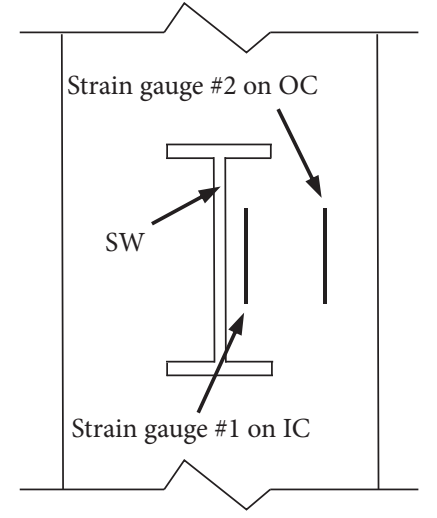

(e)

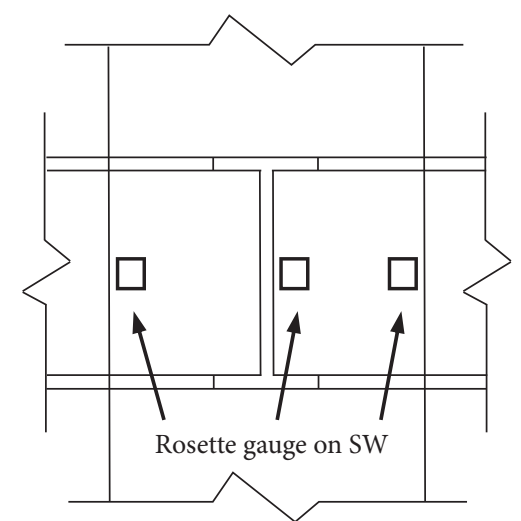

(c)

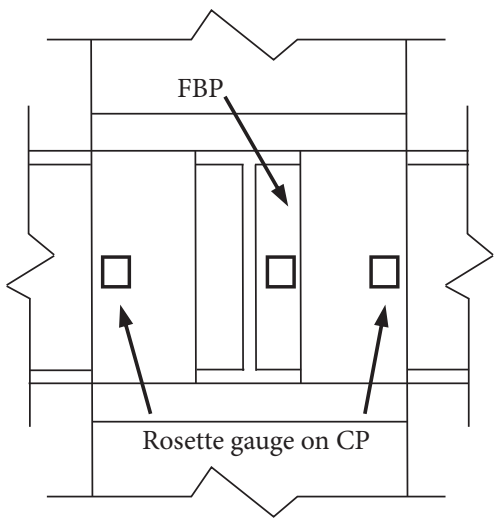

(f)

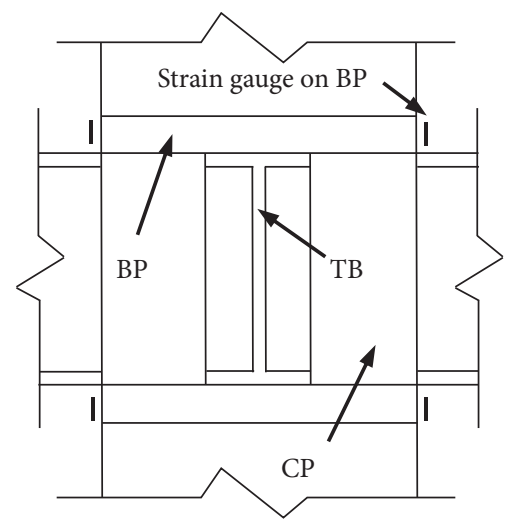

(g)

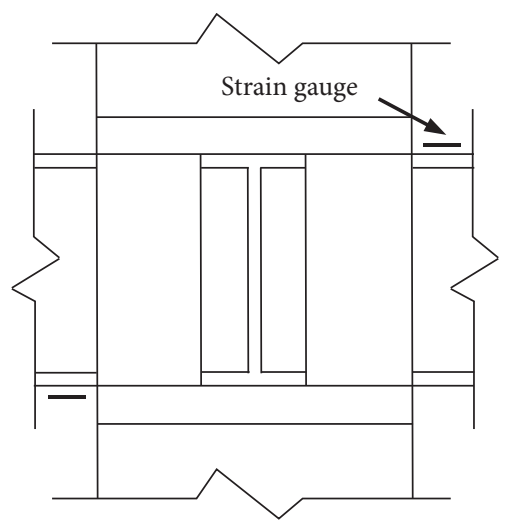

(h)

FIGURE 8: Location of strain gauges and rosette gauges: (a) strain gauges on JH, (b) strain gauges on longitudinal rebar, (c) rosette gauges on SW, (d) strain gauges on IC and OC, (e) strain gauges on IC and OC, (f) rosette gauges on CP, (g) strain gauges on BP, and (h) strain gauges on longitudinal beam flange.

4.2.2. Contribution Analysis of Shear Force. During the experiment, the shear force of the joint is very difficult to measure precisely, but in analysis, the shear force estimation of the joint can be directly executed. The shear force of joint is defined by the sum of the equivalent force passing through the middle plane of the beam-column joint. Based on analysis, every element resisting shear force on a section was chosen as shear contribution elements of the RCS joint. These elements were divided by inner element and outer element based on the location of the shear force of each element. FBP and CP were classified as the outer element.
Based on the analysis result, the element having shear force is OC, IC, SW, FBP, and CP. JH is considered as part of OC. The shear contribution ratio of each element as the load increases is shown in Figure 14. As crack on concrete occurs, the shear contribution ratio of concrete decreases, and the shear contribution ratio of SW increases. After that, the shear contribution ratio of SW decreases gradually and a similar shear contribution ratio to the initial phase occurs when the maximum strength is reached. FBP of all specimens except for SNI-I, specimen without TB, contributes about $10 \%$ of shear force. 


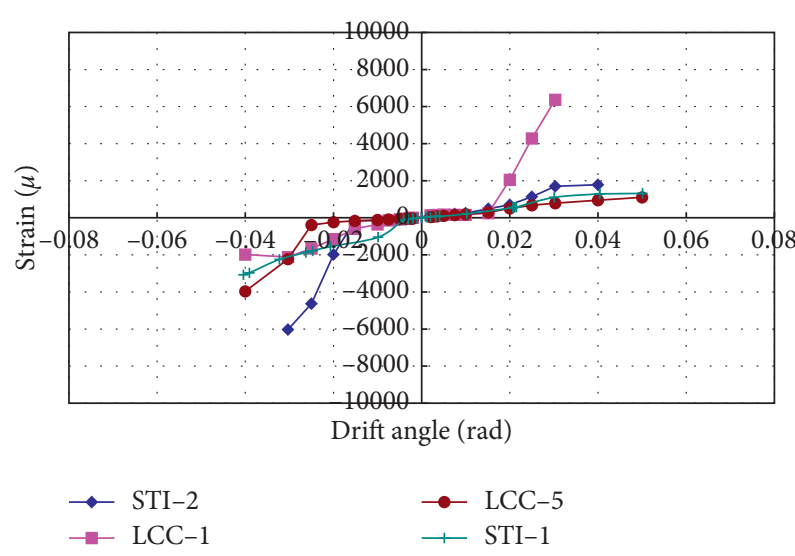

(a)

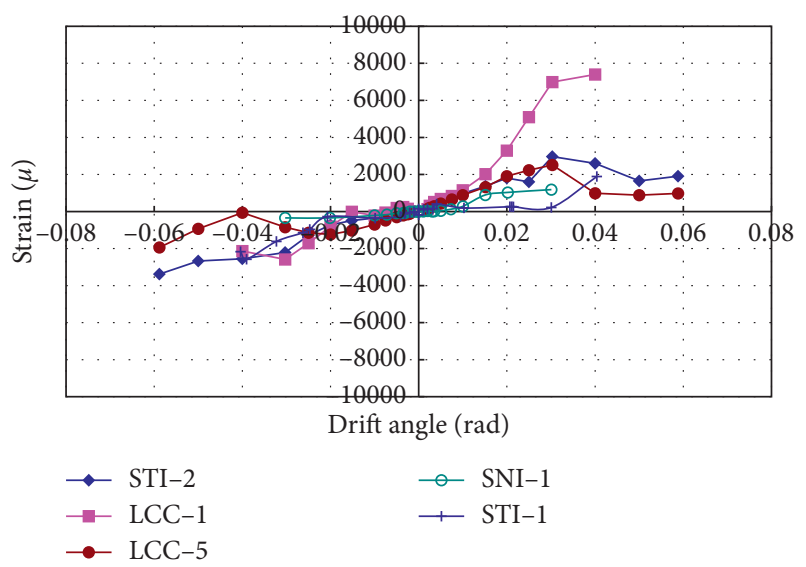

(c)
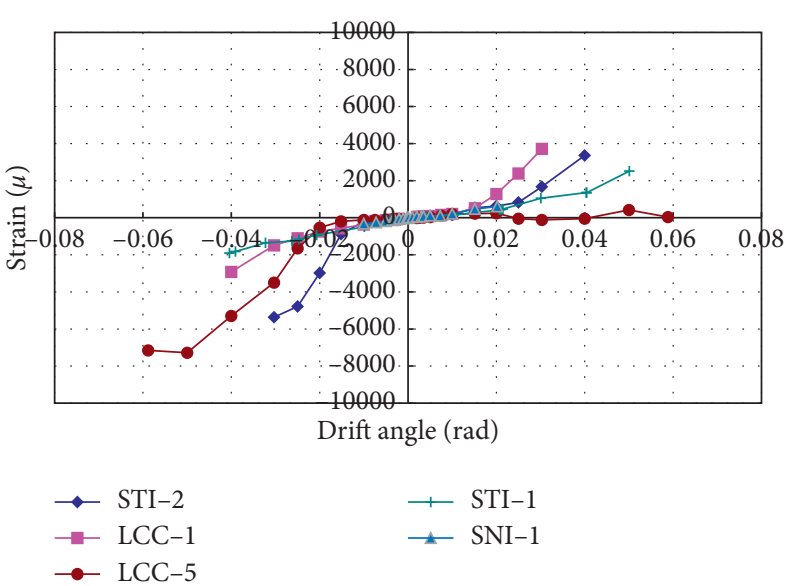

(b)

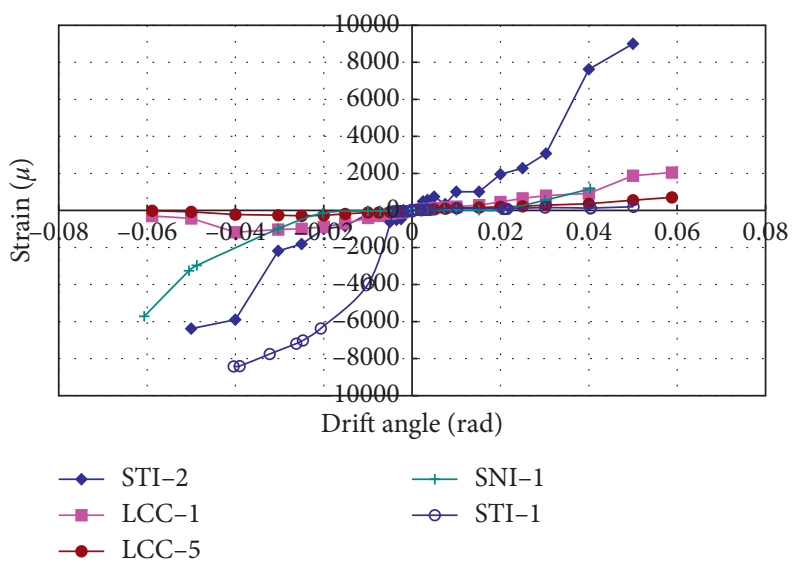

(d)

Figure 9: Strain of shear resistance elements. (a) IC, Inner Concrete. (b) OC, Outer Concrete. (c) SW, Steel Beam Web. (d) CP, Cover Plate (or stirrup).

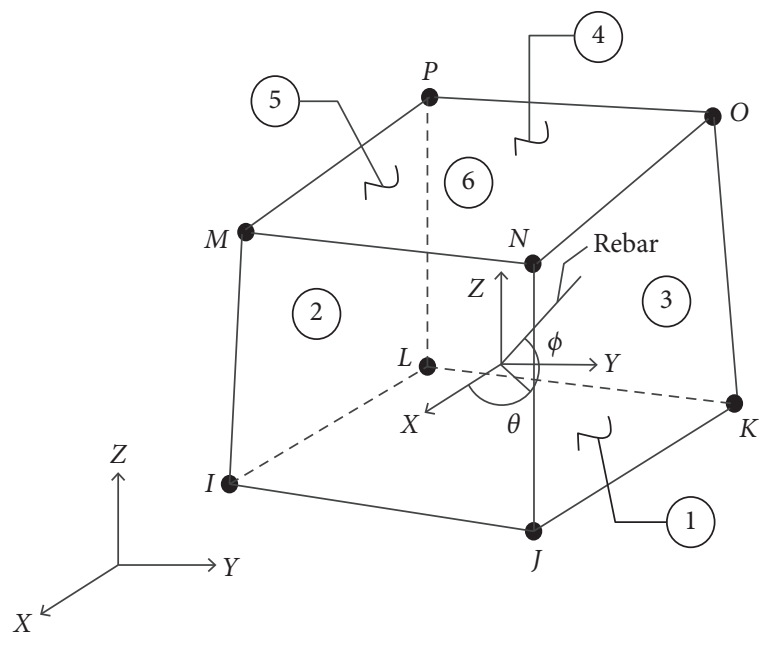

Figure 10: Geometry of 8-node solid element.

For SNI-1, 15\% of shear force is resisted by SW at the initial phase, but as crack develops and the specimen yields, the shear contribution ratio reaches approximately $35 \%$. The shear contribution ratio of IC and OC decreases that

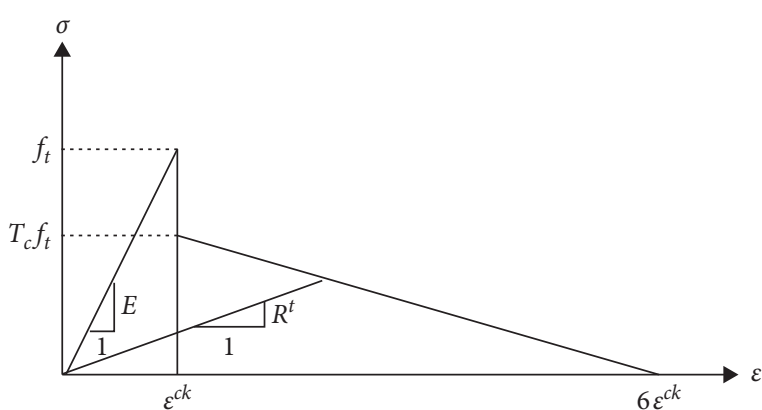

FIGURE 11: Stress-strain curve of cracked condition.

much. About $15 \%$ and $50 \%$ of shear force are resisted by OC and IC, respectively. Particularly, FBP of SNI-1 hardly supports shear force. Similar to SNI-1, the shear contribution ratio of SW of STI-1 increases up to $40 \%$ after crack, but the shear contribution ratio of SW decreases to $35 \%$ when the maximum strength is reached. OC and IC resist about $17 \%$ and $35 \%$ of the shear force, and FBP resists about $10 \%$ of the shear force consistently. For STI-2, JHtype specimen with E-FBP, OC, IC, SW, and FBP resist 


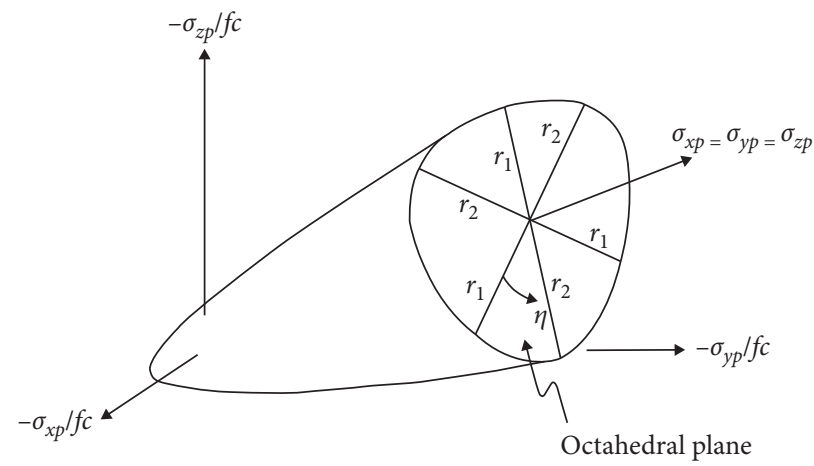

FIGURE 12: Failure surface in principal stress space.

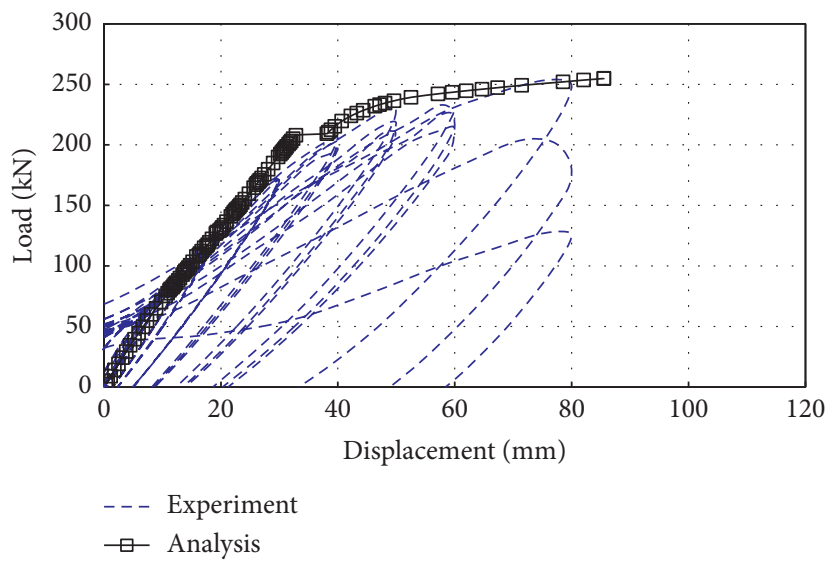

Figure 13: Load versus displacement of experiment and analysis (STI-1).

TABle 2: Comparison of strength $(\mathrm{kN})$.

\begin{tabular}{lccccc}
\hline Strength model & Analysis & $\begin{array}{c}\text { Yield strength } \\
\text { Experiment }\end{array}$ & Analysis/exp. & Analysis & $\begin{array}{c}\text { Ultimate strength } \\
\text { Experiment }\end{array}$ \\
& 189.82 & 101.24 & 1.87 & 229.18 & 212.88 \\
ANI-1 & 220.51 & 164.21 & 1.34 & 263.25 & 262.46 \\
STI-1 & 225.89 & 225.69 & 1.00 & 299.42 & 284.30 \\
STI-2 & 258.07 & 242.63 & 1.06 & 377.74 & 358.91 \\
LCC-1 & 225.79 & 228.98 & 0.99 & 270.73 & 265.74 \\
LCC-5 & & & & 1.08 \\
\hline
\end{tabular}

$13-18 \%, 19-33 \%, 35-56 \%$, and $10-15 \%$ of shear force, respectively.

For LCC-1, CP-type shear failure specimen, OC, IC, SW, FBP, and CP resist 4-8\%, 16-28\%, 25-48\%, 12-18\%, and $15-23 \%$ of shear force, respectively. The contribution of shear force resistance of OC decreased remarkably due to the effect of CP. However, when the contribution ratios of OC and $\mathrm{CP}$ are added, their contribution ratio of shear is about $14 \%$ larger than that of STI-2. Hence, the shear force of the RCS joint of the CP-type specimen is larger than that of the JH-type specimen. However, the existing shear strength equation is not able to reflect these effects properly. For LCC-5, CP-type moment failure specimen, OC, IC, SW, FBP, and CP resist 4-7\%, 16-26\%, 34-53\%, 11-16\%, and $13-19 \%$ of shear force, respectively. Compared to the CP- type shear failure specimen, contribution of shear force resistance of SW of LCC5 is larger than that of concrete. For LCC-5, the effect of CP is somewhat decreased compared to LCC-1.

Figure 15 shows the change of shear resisting contribution of each element as the load increases. As shown in Figure 15(a), for OC, shear force resistance of the JH-type specimen is much larger than that of the CP-type specimen under the same load condition. It is because the contribution of shear force of OC at joint decreases due to the constraint effect of CP. Also, as shown in Figure 15(b), for IC, shear force resistance of JH-type specimen is much larger than $\mathrm{CP}$ type specimen. IC of LCC-1, which is the specimen where a large amount of shear force is resisted by $\mathrm{CP}$, resists about $40 \%$ less shear force than that of STI-2. 


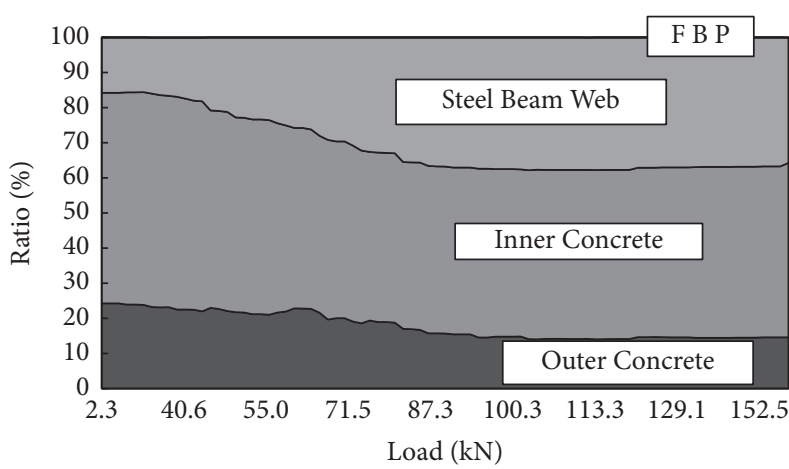

(a)

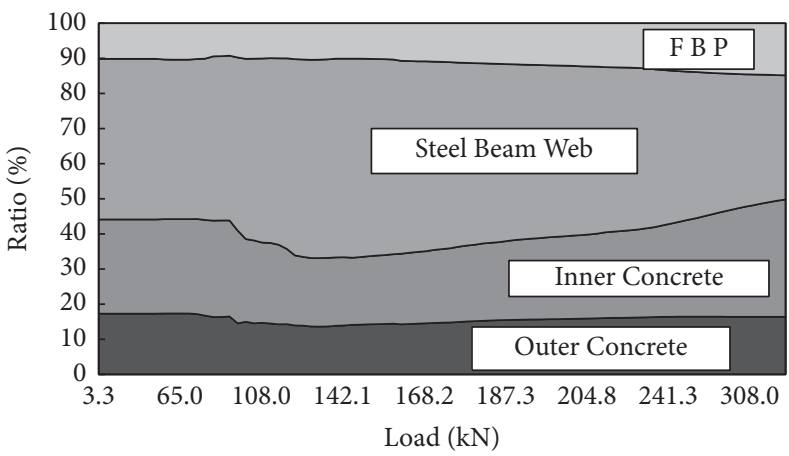

(c)

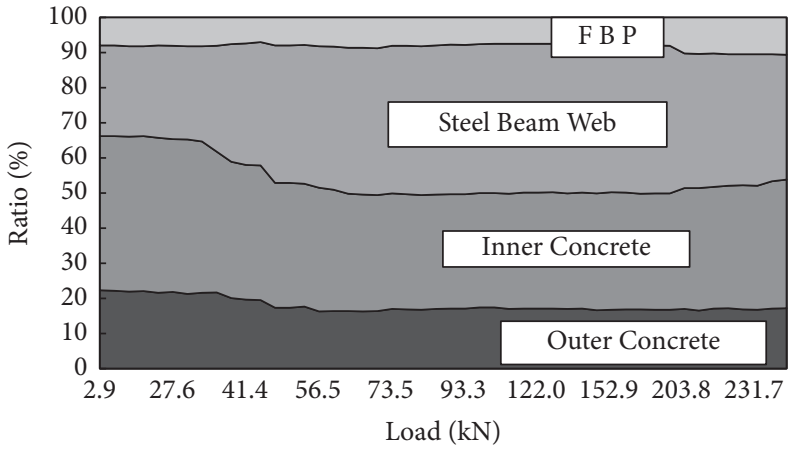

(b)

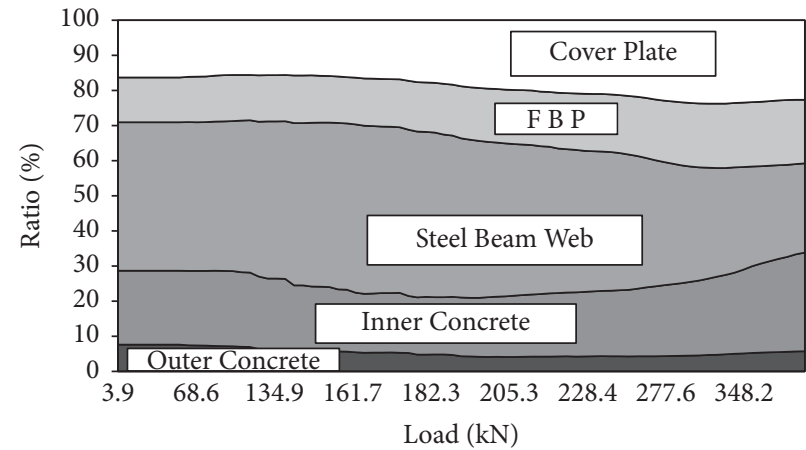

(d)

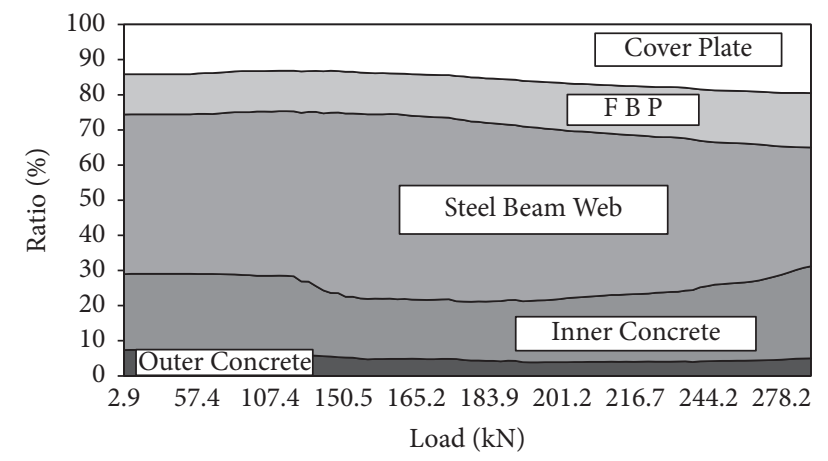

(e)

Figure 14: Shear contribution ratio. (a) SNI-1. (b) STI-1. (c) STI-2. (d) LCC-1. (e) LCC-5.

For JH-type specimen, IC of STI-2, the specimen with TB and E-FBP, resists the smallest amount of shear force, and the next smallest resistance of shear force belongs to IC of STI-1, the specimen with TB. Shear resistance contribution of IC tends to decrease when reinforced element increases.

As shown in Figure 15(c), the shear force resistance of SW is similar in all specimens and shear force is uniformly resisted. As shown in Figure 15(d), FBP's shear force resistance of all specimens except SNI-1 displays a similar tendency. As shown in Figure 15(e), CP's shear force resistance of LCC- 1 and LCC- 5 presents similar characteristics in the beginning, but eventually CP of LCC- 1 displays a little bit larger shear force than that of LCC-5. It is because CP of LCC- 1 is the first element subjected to stress when the load is transferred to the joint, and the restraint effect of $\mathrm{CP}$ protects OC. The shear force of CP of LCC- 1 is about $11 \%$ larger than that of LCC-5, while the shear force of OC shows small differences. The shear force of the inner element of LCC- 5 is larger than that of LCC- 1 because after the steel beam of LCC-5 yields, stress is transferred to SW and IC of the joint.

4.2.3. Comparison with the Existing Shear Force Equation of RCS Joint. Table 3 shows a comparison of the shear contribution ratio found from the equations proposed by ASCE and Kanno and that of finite element analysis when the maximum strength is reached. It is obvious that these equations have a problem estimating accurate shear strength contribution of TB, E-FBP, and CP. Shear strength equations of the RCS joint proposed by ASCE and Kanno are represented by the inner element and outer element. In this research, the inner element consists of IC and SW, and the outer element consists of OC, JH, FBP, and CP. 

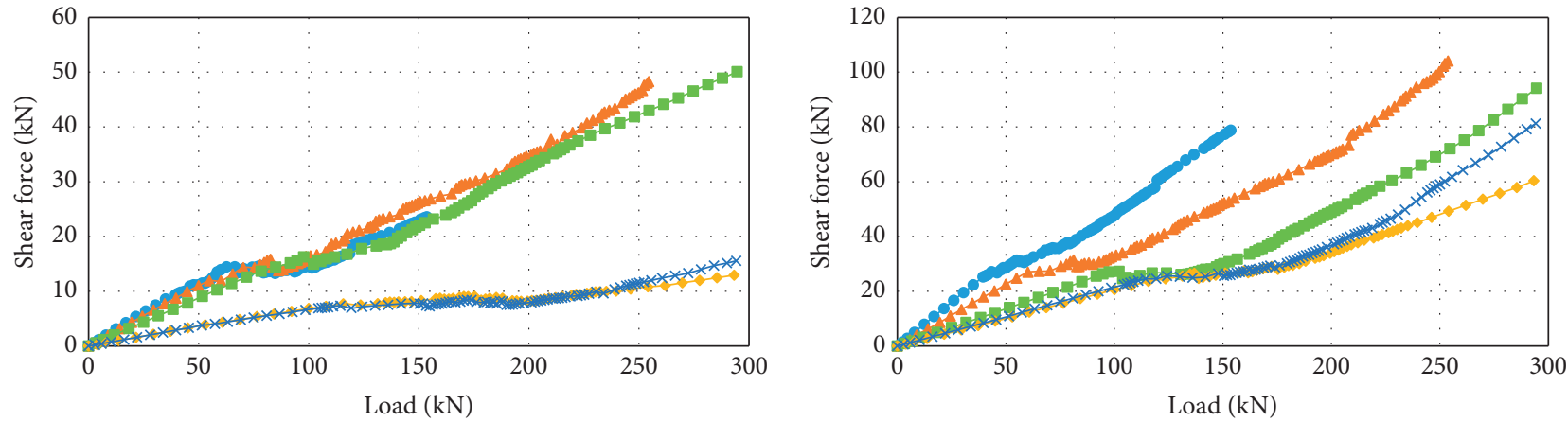

$\rightarrow$ SNI-1
$\simeq$ STI-1
$\rightarrow$ STI-2

$\rightarrow-$ LCC-1

$*$ LCC -5

(a)

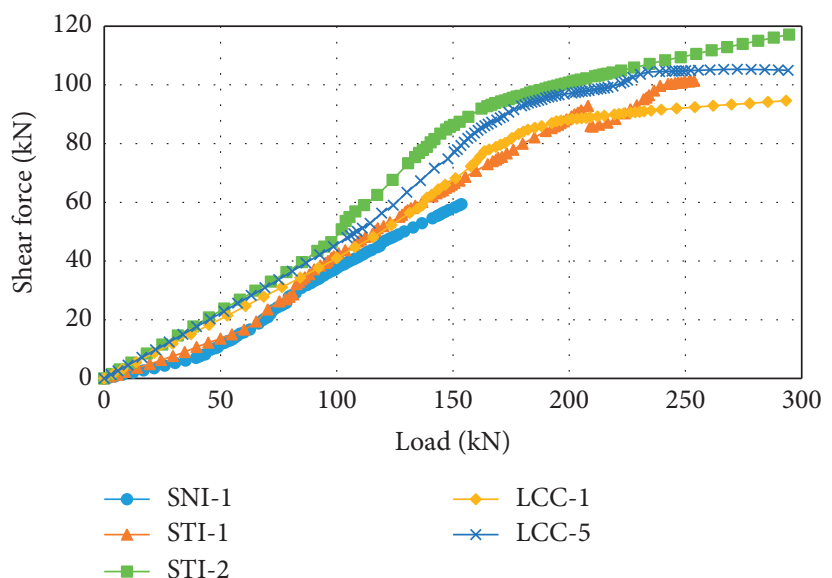

(c)

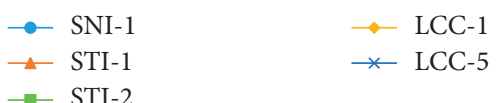

(b)
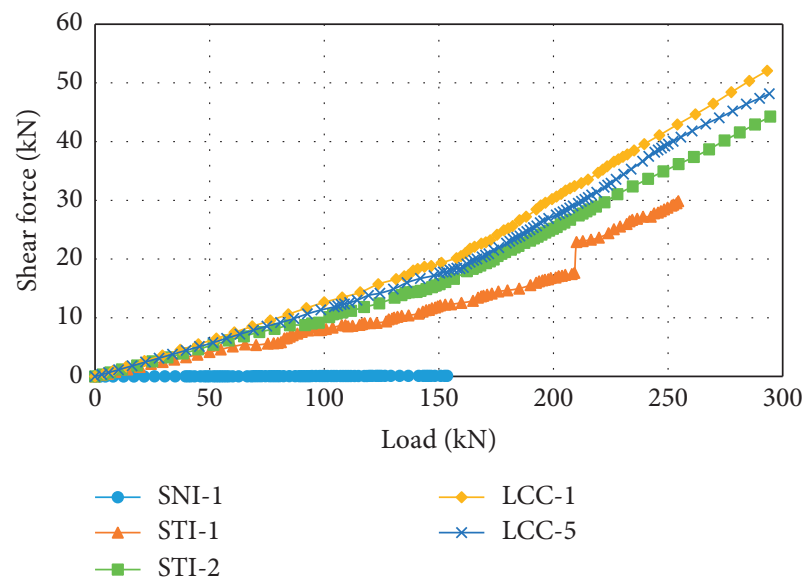

$\rightarrow$ LCC- 1

$*$ LCC -5

(d)

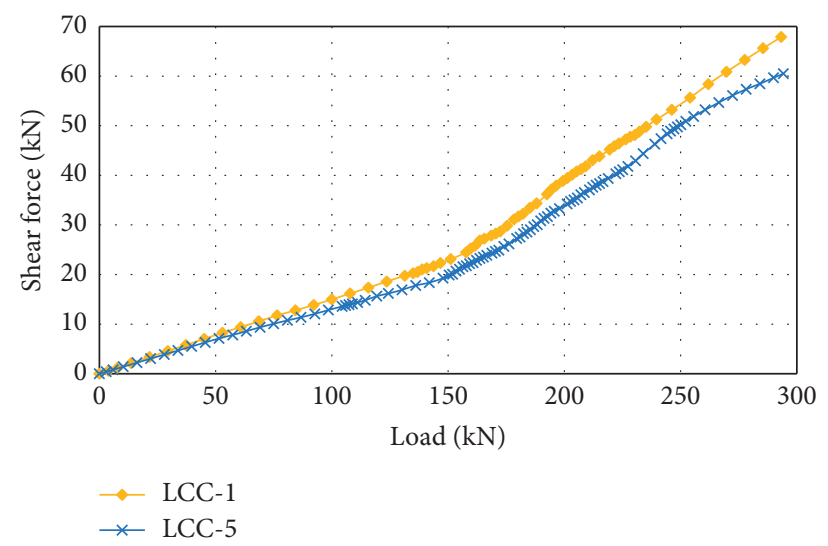

(e)

Figure 15: Shear strength contribution. (a) OC, Outer Concrete. (b) IC, Inner Concrete. (c) SW, Steel Beam Web. (d) FBP, Face Bearing Plate. (e) CP, Cover Plate.

TABLe 3: Shear contribution ratio (\%).

\begin{tabular}{lcccc}
\hline Specimen & Division & FEM & ASCE & M-Kanno \\
\multirow{2}{*}{ SNI-1 } & Inner & 85.34 & 85.35 & 78.31 \\
& Outer & 14.66 & 14.65 & 21.68 \\
\hline \multirow{2}{*}{ STI-1 } & Inner & 72.53 & 85.42 & 65.02 \\
& Outer & 27.47 & 14.56 & 34.97 \\
\hline \multirow{2}{*}{ STI-2 } & Inner & 68.8 & 82.3 & 45.47 \\
& Outer & 31.2 & 17.7 & 54.52 \\
\hline \multirow{2}{*}{ LCC-1 } & Inner & 53.5 & 63.8 & 42.79 \\
& Outer & 46.5 & 36.2 & 57.2 \\
\hline
\end{tabular}




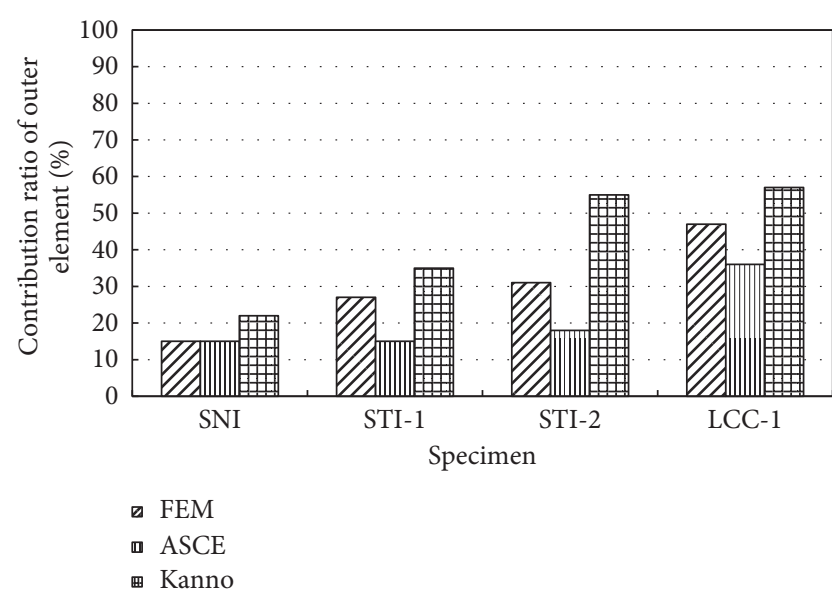

FIGURE 16: Shear contribution ratio of the outer element.

Kanno considered FBP and CP as the inner element, but, in this study, the classification of the inner element and outer element was modified for analysis. Because of modification, deciding the reasonable effective value of the outer element was critical to the result. However, it was not possible to find the value that resulted in accurate outer element strength from Kanno's procedure. As shown in Figure 16, the ASCE equation underestimates the contribution of the outer element, and M-Kanno equation tends to overestimate it. Although M-Kanno equation anticipates shear strength fairly well, it overestimates the shear contribution ratio of the outer element. This may result in a big difference when the details of the RCS joint are changed.

\section{Conclusion}

(1) A comparison between the experimental value and analysis value was executed. For all cases, the initial stiffness was excellently anticipated, which was within $10 \%$ error. Most strengths from the analysis were reasonably calculated within $10 \%$ error excluding the yield strengths of SNI-1 and STI-1.

(2) The maximum shear strength of SNI-1, STI-1, STI-2, and LLC-1, calculated from the analysis, was $229.18 \mathrm{kN}, 263.25 \mathrm{kN}, 299.42 \mathrm{kN}$, and $377.74 \mathrm{kN}$, respectively. TB, E-FBP, and CP increased the shear force by about $15 \%, 14 \%$, and $26 \%$, respectively. To find TB's effect on increasing shear strength of joint, the strength of SNI-1 and STI-1 is compared because the only difference between SNI-1 and STI-1 is TB. A similar approach is used for finding the shear force increasing effect of E-FBP and CP. TB, E-FBP, and CP provided additional confinement to STI-1, STI-2, and LLC-1, respectively, and these shear resistance elements significantly affected the increase of the shear strength of the joint.

(3) For JH-type joints, the shear strength of the RCS joint is contributed by $70 \%$ from the inner element and $30 \%$ from the outer element.
(4) For CP-type joints, the shear strength contribution ratio of the outer element increases compare to that of JH-type joints. This results in a significant increase of the total shear strength of CP-type joints. CP prevents the stress concentration at $\mathrm{OC}$ and supports most of the outer element contribution to shear force resistance at the RCS joint.

(5) ASCE equation underestimates the contribution of the outer element, and M-Kanno equation tends to overestimate it.

\section{Data Availability}

The data used to support the findings of this study are available from the corresponding author upon request.

\section{Conflicts of Interest}

The authors declare no conflicts of interest.

\section{Acknowledgments}

This work was supported by Korea Research Foundation Grant funded by the Korean Government (KRF-2005-050-D00017). The authors wish to express their gratitude for the financial support.

\section{References}

[1] L. G. Griffis, "Composite frame construction," in Constructional Steel Design, P. J. Dowling, J. E. Harding, and R. Bjorhovde, Eds., pp. 523-554, Elsevier Applied Sciences, New York, NY, USA, 1992.

[2] M. N. Bugeja, J. M. Bracci, and W. P. Moore, "Seismic behavior of composite RCS frame systems," Journal of Structural Engineering, vol. 126, no. 4, pp. 429-436, 2000.

[3] I. Nishiyama, H. Kuramoto, and H. Noguchi, "Guidelines: seismic design of composite reinforced concrete and steel buildings," Journal of Structural Engineering, vol. 130, no. 2, pp. 336-342, 2004.

[4] M. Wakabayashi, K. Minami, and Y. Nishimura, "Load carrying capacity of composite exterior joint with steel beam," Transactions of the Japan Concrete Institute, vol. 5, pp. 339346, 1983.

[5] I. Nishiyama, “"Design methods and problems on composite structures", no.9, III-7," Concrete Journal, vol. 28, no. 10, pp. 70-76, 1990.

[6] N. Sakaguchi, "Shear capacity of beam-column connection between steel beams and reinforced concrete columns," Journal of Structural and Construction Engineering (Transactions of AIJ), vol. 428, pp. 69-78, 1991.

[7] Y. Murata, S. Fujimoto, and R. Yanagi, "Experiment on concrete bearing failure in the composite system with steel beam going through the reinforced concrete column," in Proceedings of the Symposium on Structural Behavior of Composite Structure with Steel Beam and Reinforced Concrete Column, pp. 41-46, Tokyo, Japan, 1994.

[8] T. M. Sheikh, G. G. Deierlein, J. A. Yura, and J. O. Jirsa, "Beam-column moment connections for composite frames: part 1," Journal of Structural Engineering, vol. 115, no. 11, pp. 2858-2876, 1989. 
[9] Y. Nishimura and K. Minami, "Stress transfer from steel beams to reinforced concrete columns," in Proceedings of the ISABE Symposium Proceeding: Mixed Structures Including New Materials, pp. 384-394, Zurich, Switzerland, 1990.

[10] G. G. Deierlein, T. M. Sheikh, J. A. Yura, and J. O. Jirsa, "Beam-column moment connections for composite frames: part 2," Journal of Structural Engineering, vol. 115, no. 11, pp. 2877-2896, 1989.

[11] ASCE, "ASCE task committee on design criteria for composite structures in steel and concrete, "guidelines for design of joints between steel beams and reinforced concrete columns"," Journal of Structural Engineering, ASCE, vol. 120, no. 8, pp. 2330-2357, 1994.

[12] R. Kanno, Strength, Deformation, and Seismic Resistance of Joints between Steel Beams and Reinforced Concrete Columns, Cornell University, Ithaca, NY, USA, 1993.

[13] R. Kanno, "Evaluation of existing strength models for RCS joints and consideration toward improved modeling: a study on strength evaluation of RCS joints part 1," Journal of Structural and Construction Engineering (Transactions of AIJ), vol. 67, no. 553, p. 135, 2002.

[14] G. G. Deierlein and H. Noguchi, "Overview of U.S.-Japan research on the seismic design of composite reinforced concrete and steel moment frame structures," Journal of Structural Engineering, vol. 130, no. 2, pp. 361-367, 2004.

[15] X. Liang and G. J. Parra-Montesinos, "Seismic behavior of reinforced concrete column-steel beam subassemblies and frame systems," Journal of Structural Engineering, vol. 130, no. 2, pp. 310-319, 2004.

[16] P. P. Cordova and G. G. Deierlein, "Validation of the seismic performance of composite RCS frames: full-scale testing, analytical modeling, and seismic design," John A. Blume Earthquake Engineering Center Technical Report, vol. 155, 2005.

[17] C.-T. Cheng and C.-C. Chen, "Seismic behavior of steel beam and reinforced concrete column connections," Journal of Constructional Steel Research, vol. 61, no. 5, pp. 587-606, 2005.

[18] W. Li, Q.-N. Li, W.-S. Jiang, and L. Jiang, "Seismic performance of composite reinforced concrete and steel moment frame structures-state-of-the-art," Composites Part B: Engineering, vol. 42, no. 2, pp. 190-206, 2011.

[19] B. F. Azar, H. Ghaffarzadeh, and N. Talebian, "Seismic performance of composite RCS special moment frames," KSCE Journal of Civil Engineering, vol. 17, no. 2, pp. 450-457, 2013.

[20] S. Alizadeh, N. K. A. Attari, and M. T. Kazemi, "The seismic performance of new detailing for RCS connections," Journal of Constructional Steel Research, vol. 91, pp. 76-88, 2013.

[21] X. H. Nguyen, D. D. Le, and Q. H. Nguyen, "Static behavior of novel RCS through-column-type joint: experimental and numerical study," Steel and Composite Structures, vol. 32, no. 1, pp. 111-126, 2019.

[22] R. Jafari, N. K. Attari, A. Nikkhoo, and S. Alizadeh, "Simplified method for modeling reinforced concrete column-steel beam connections with tube plate," Advances in Structural Engineering, vol. 23, no. 11, pp. 2292-2304, 2020.

[23] S. Ghods, A. Kheyroddin, M. Nazeryan, S. M. Mirtaheri, and M. Gholhaki, "Nonlinear behavior of connections in RCS frames with bracing and steel plate shear wall," Steel and Composite Structures, vol. 22, no. 4, pp. 915-935, 2016.

[24] ACI, "Acceptance criteria for moment frames based on testing," in ACI Innovative Task Group 1 and CollaboratorsAmerican Concrete Institute, Detroit, MI, USA, 2001.
[25] J. S. Stehle, H. Goldsworthy, and P. Mendis, "Reinforced concrete interior wide-band beam-column connections subjected to lateral earthquake loading," ACI Structural Journal, vol. 98, no. 3, pp. 270-279, 2001.

[26] K. J. Willam and E. P. Warnke, "Constitutive model for the triaxial behavior of concrete," in Proceedings of the International Association for Bridge and Structural Engineering, p. 174, Bergamo, Italy, 1975. 